\title{
Recurrent Bleeding from a Hepatic Artery Pseudoaneurysm after Biliary Stent Placement
}

\author{
Kenji Yamauchi, Daisuke Uchida, Hironari Kato and Hiroyuki Okada
}

\begin{abstract}
:
A 78-year-old woman was admitted with benign biliary stenosis. A plastic stent was placed at the left branch to prevent obstructive cholangitis. Two weeks after the procedure, the patient was readmitted with cholangitis caused by hemobilia. However, computed tomography (CT), endoscopic retrograde cholangiopancreatography (ERCP), peroral cholangioscopy, and abdominal angiography failed to establish the bleeding source. At the seventh bleeding, CT revealed a hepatic artery pseudoaneurysm for which coil embolization was successfully performed. Hemobilia after plastic stent placement is extremely rare. We urge clinicians to consider the possibility of a pseudoaneurysm near the stent when trying to identify the bleeding source.
\end{abstract}

Key words: hemobilia, hepatic artery pseudoaneurysm, plastic stent

(Intern Med 57: 49-52, 2018)

(DOI: 10.2169/internalmedicine.8983-17)

\section{Introduction}

Hemobilia causes symptoms such as upper abdominal pain, upper gastrointestinal bleeding, and jaundice, the combination of which is known as Quincke's triad due to bleeding in the bile duct. The main causes of hemobilia are iatrogenic and include liver biopsy or percutaneous biliary drainage. Hemobilia as a complication of plastic stent placement is exceedingly rare. To the best of our knowledge, there have only been five previously reported cases. In the present case, 2 weeks after the first plastic stent placement, the patient needed to be admitted 7 times for recurrent intermittent biliary bleeding. Several factors are associated with hemobilia after plastic stent placement. It was recently reported that endoscopic retrograde cholangiopancreatography (ERCP)-related bile duct injury, malignant tumor invasion, cholangitis, and liver abscess may contribute to hemobilia. In the present case, benign biliary stricture, recurrent cholangitis, and long-term steroid use are presumed to be the cause of hemobilia.

\section{Case Report}

A 78-year-old woman was admitted for biliary stenosis and protracted cholangitis after undergoing endoscopic sphincterotomy (EST) for the treatment of biliary calculi. The patient had taken oral prednisolone for the treatment of autoimmune hepatitis for over a decade. She took oral psednisolone $30 \mathrm{mg} / \mathrm{day}$ as the initial treatment. After the usual tapering of the prednisolone to a maintenance dose of 10 $\mathrm{mg}$, she received maintenance therapy for 10 years.

Her abdomen was soft and flat and no mass was palpable on physical examination. Laboratory findings revealed an elevated level of lactate dehydrogenase [253 IU/L (normal range, 124-222 IU/L)] and decreased level of albumin [3.4 $\mathrm{g} / \mathrm{dL}$ (normal range, 3.8-5.2 g/dL)] (Table 1). ERCP and brush cytology revealed benign biliary stricture caused by recurrent cholangitis due to duodenal content reflux after EST (Fig. 1, arrow). A plastic stent was placed at the left branch (B3) to prevent obstructive cholangitis without causing any injury to the bile duct.

Two weeks after the procedure, the patient was readmitted with cholangitis caused by hemobilia. ERCP revealed pulsating bleeding from the bile duct. The bleeding was ar-

Departments of Gastroenterology and Hepatology, Okayama University Graduate School of Medicine, Dentistry, and Pharmaceutical Sciences, Japan

Received: February 5, 2017; Accepted: May 10, 2017; Advance Publication by J-STAGE: October 16, 2017

Correspondence to Dr. Kenji Yamauchi, yamauchi.kenji@hotmail.com 
Table 1. Laboratory Data at Presentation.

\begin{tabular}{lclrlc}
\hline & Unit & & Unit & Unit \\
\hline WBC & $6,340 / \mu \mathrm{L}$ & Total bilirubin & $1 \mathrm{~g} / \mathrm{dL}$ & $\mathrm{Na}$ & $146 \mathrm{mEq} / \mathrm{L}$ \\
RBC & $391 \times 10^{4} / \mu \mathrm{L}$ & Direct bilirubin & $0.2 \mathrm{~g} / \mathrm{dL}$ & $\mathrm{K}$ & $4.1 \mathrm{mEq} / \mathrm{L}$ \\
Hemoglobin & $12.7 \mathrm{~g} / \mathrm{dL}$ & AST & $22 \mathrm{IU} / \mathrm{L}$ & $\mathrm{Cl}$ & $106 \mathrm{mEq} / \mathrm{L}$ \\
Hematocrit & $38.2 \%$ & ALT & $15 \mathrm{IU} / \mathrm{L}$ & $\mathrm{CRP}$ & $0.16 \mathrm{mg} / \mathrm{dL}$ \\
Platelets & $22.3 \times 10^{4} / \mu \mathrm{L}$ & LDH & $\underline{253} \mathrm{IU} / \mathrm{L}$ & $\mathrm{CA} 19-9$ & $21 \mathrm{U} / \mathrm{mL}$ \\
PT & $113 \%$ & ALP & $184 \mathrm{IU} / \mathrm{L}$ & $\mathrm{CEA}$ & $4.6 \mathrm{ng} / \mathrm{mL}$ \\
APTT & $\underline{25.6} \mathrm{sec}$ & $\gamma-\mathrm{GTP}$ & $30 \mathrm{IU} / \mathrm{L}$ & $\mathrm{DUPAN}-2$ & $\underline{164} \mathrm{U} / \mathrm{mL}$ \\
Total protein & $25.6 \mathrm{~g} / \mathrm{dL}$ & BUN & $14 \mathrm{mg} / \mathrm{dL}$ & & \\
Albumin & $\underline{3.4 \mathrm{~g} / \mathrm{dL}}$ & Creatinine & $0.7 \mathrm{mg} / \mathrm{dL}$ & & \\
\hline
\end{tabular}

Underlines show the values outside the reference ranges.

WBC: white blood cells, RBC: red blood cells, PT: prothrombin time, APTT: activated partial thromboplastin time, AST: aspartate aminotransferase, ALT: alanine aminotransferase, LDH: lactate dehydrogenase, ALP: alkaline phosphatase, $\gamma$-GTP: gamma-glutamyl transferase, BUN: blood urea nitrogen, CRP: C-reactive protein, CA19-9: carbohydrate antigen 19-9, CEA: carcinoembryonic antigen, DUPAN-2: duke pancreatic monoclonal antigen type 2

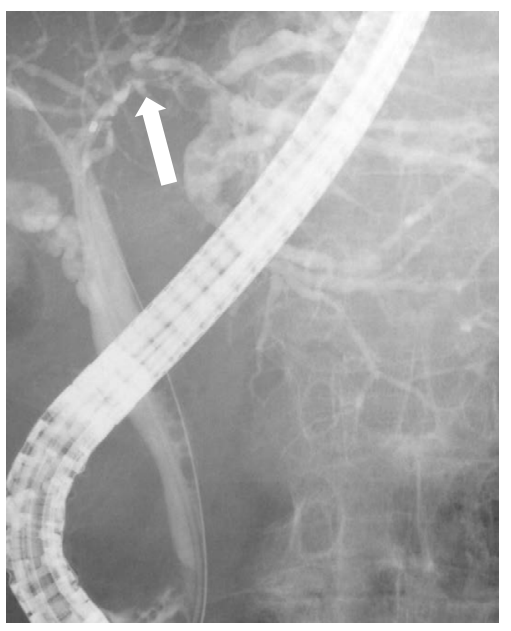

Figure 1. Endoscopic retrograde cholangiopancreatography image showing biliary stricture. A plastic stent was placed to prevent obstructive cholangitis.

rested by replacing the plastic stent (Fig. 2), but the bleeding source could not be identified on subsequent angiography.

After the first bleeding, the patient needed to be admitted six times over 6 months for recurrent intermittent bleeding. However, CT, ERCP, and peroral cholangioscopy failed to establish the bleeding source. At the seventh bleeding, computed tomography (CT) revealed the extravasation of contrast dye to the bile duct (Fig. 3A, arrow) and the presence of a hepatic artery aneurysm (Fig. 3B, arrow). Threedimensional CT angiography also revealed an aneurysm that developed at the side of the stent (Fig. 4, arrow). The aneurysn measured about $3 \mathrm{~mm}$ in diameter. Angiography revealed an aneurysm at the bifurcation of segment 2 and 3 branches of the left hepatic artery (Fig. 5, arrow). Successful coil embolization of the left hepatic artery pseudoaneurysm was performed. No recurrent bleeding occurred over the following days (Fig. 6).

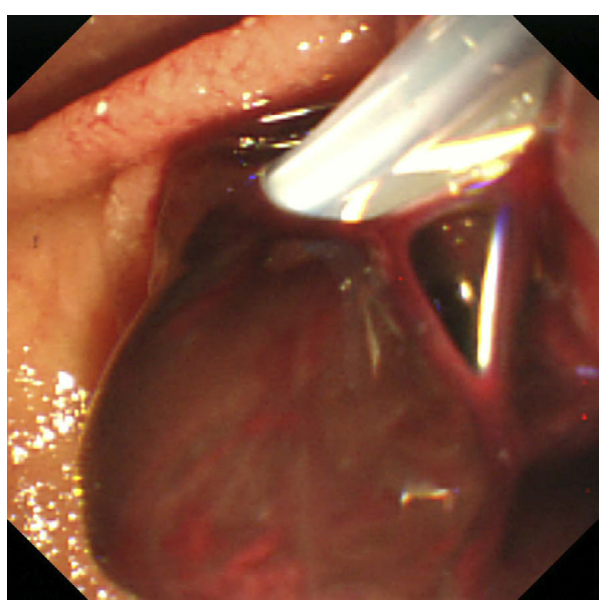

Figure 2. Endoscopic scan showing active bleeding from the duodenal papilla.

\section{Discussion}

Hemobilia causes symptoms, such as upper abdominal pain, upper gastrointestinal bleeding, and jaundice, the combination of which is known as Quincke's triad due to bleeding in the bile duct (1). The main causes of hemobilia are iatrogenic and include liver biopsy or percutaneous biliary drainage (2). Apart from iatrogenic bleeding, malignant tumor is the main cause (3). In this case, a hepatic artery pseudoaneurysm after plastic stent placement for benign biliary stricture caused the hemobilia.

Hepatic artery pseudoaneurysm as a complication of plastic stent placement for benign biliary stricture is rare. Pseudoaneurysm formation by metal stent placement for malignant biliary obstruction is reported to occur in $1.2 \%$ of cases (4). In contrast to metal stents, plastic stents seem to very rarely cause pseudoaneurysm. However, the exact prevalence remains uncertain. To the best of our knowledge, there have only been five previously reported cases of 
hemobilia caused by plastic stent placement (5-9). The characteristics of these five cases in addition to the case described herein are presented in Table 2. These cases included five women and one man 59-78 years of age. The symptoms of hemobilia appeared several weeks to several months before presentation. In almost all cases, the bleeding source was identified on CT.

Several factors are associated with hemobilia after plastic stent placement. ERCP-related bile duct injury $(6,9)$, malignant tumor invasion $(5,8)$, cholangitis $(7,8)$, and liver abscess (7) may also contribute to hemobilia. In this case, we suspect that the stent was the primary cause of the aneurysm
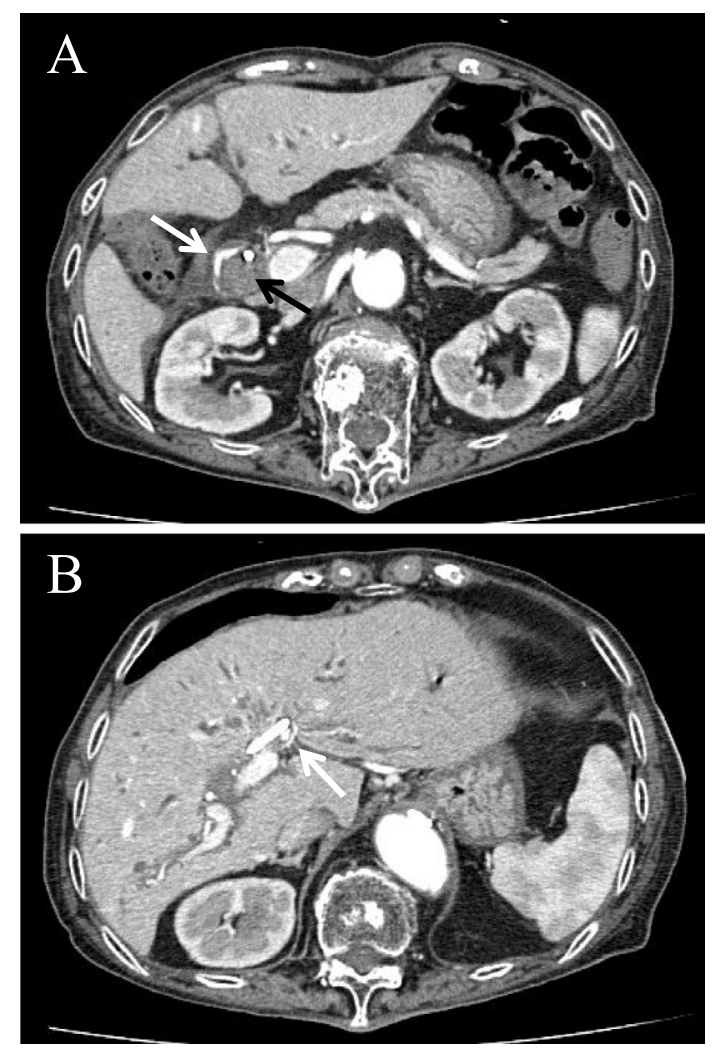

Figure 3. (A) Computed tomography scan during the arterial phase showing extravasation of the contrast dye to the main bile duct (white arrow) and distention of the common bile duct with hematoma formation (black arrow). (B) A hepatic artery aneurysm near the plastic stent (white arrow). because it developed at the same location as the stent.

However, this may not be the only cause. Recurrent cholangitis with increased intrabiliary pressure and inflammation may affect the formation of aneurysms (7). Of the 222

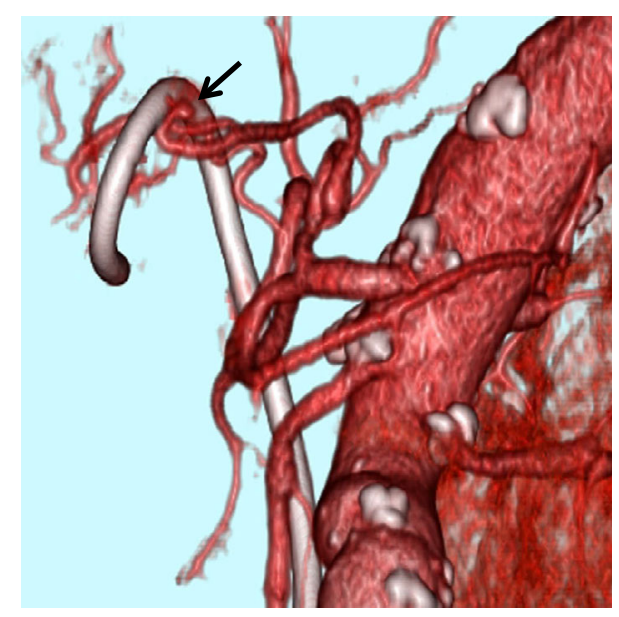

Figure 4. Three-dimensional computed tomography angiography image showing an aneurysm that developed adjacent to the stent.

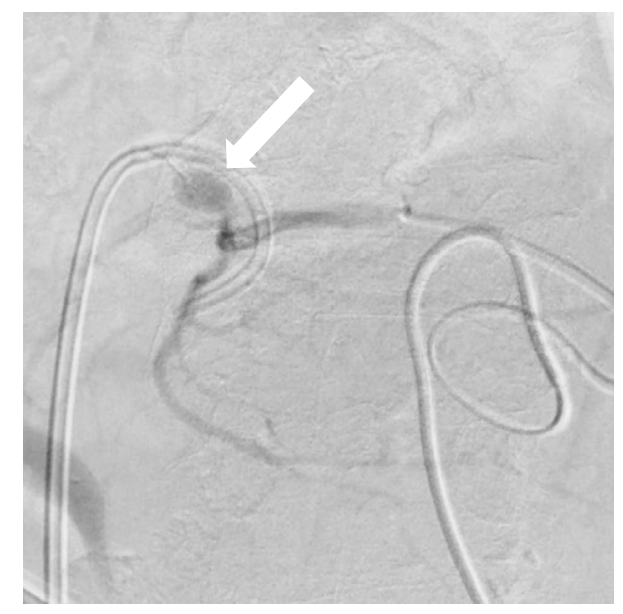

Figure 5. Angiography image showing an aneurysm at the bifurcation of branches 2 and 3 of the left hepatic artery. Coil embolization of the left hepatic artery pseudoaneurysm was successfully performed.

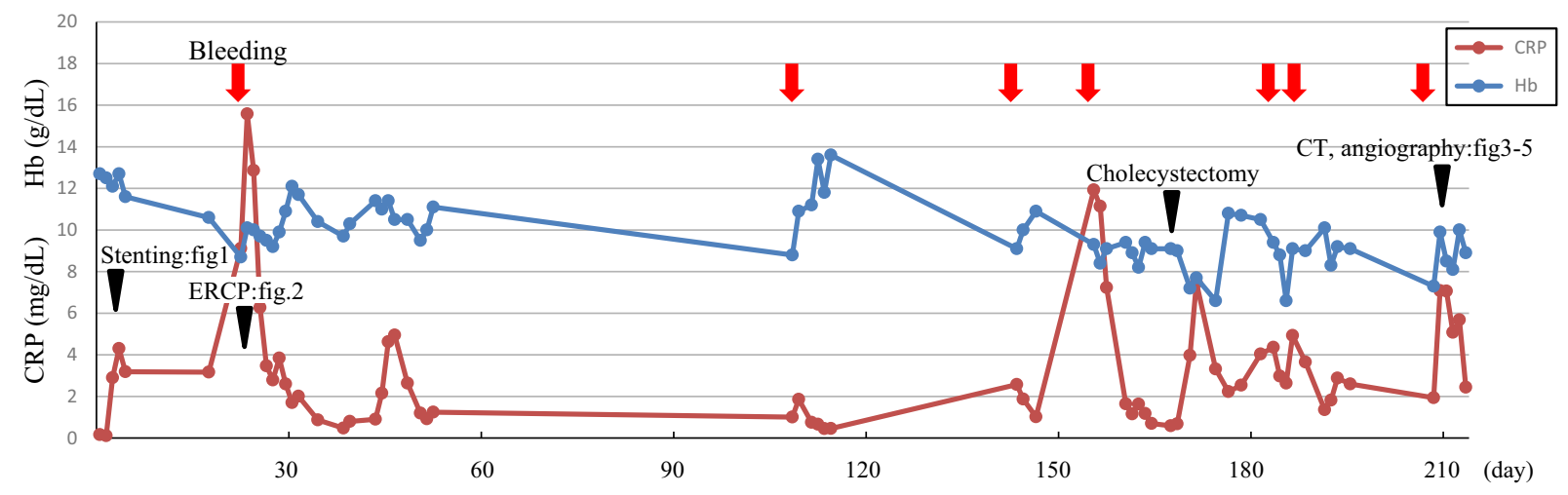

Figure 6. Clinical course. 
Table 2. Review of Case Reports on Hemobilia Caused by Plastic Stent Placement.

\begin{tabular}{|c|c|c|c|c|c|c|}
\hline No. & Reference & Age & Sex & Underlying disease & Bleeding source & $\begin{array}{l}\text { Time to } \\
\text { hemobilia }\end{array}$ \\
\hline 1 & 5 & 59 & female & $\begin{array}{c}\text { metastasis of ovarian } \\
\text { carcinoma }\end{array}$ & unspecified & unspecified \\
\hline 2 & 6 & 75 & male & pancreatic pseudocysts & arteriobiliary fistula after bile duct injury & 3 weeks \\
\hline 3 & 7 & 62 & female & Klatskin's tumor & hepatic artery pseudoaneurysm & 2 months \\
\hline 4 & 8 & 68 & female & Klatskin's tumor & hepatic artery pseudoaneurysm & 3 weeks \\
\hline 5 & 9 & 75 & female & cholangitis & $\begin{array}{l}\text { arteriobiliary fistula after perforation of } \\
\text { the bile duct }\end{array}$ & 5 weeks \\
\hline 6 & $\begin{array}{l}\text { present } \\
\text { case }\end{array}$ & 78 & female & benign biliary stricture & hepatic artery pseudoaneurysm & 2 weeks \\
\hline
\end{tabular}

cases of hemobilia reported between January 1996 and December 1999, 11 cases (5\%) demonstrated an etiology associated with cholangitis (10). Moreover, long-term steroid use might have also contributed to the weakness of the bile ducts. Chronic steroid use has been reported to make the arterial walls fragile (11). CT finally revealed the bleeding source after the seventh episode of hemobilia due to a slowly expanding pseudoaneurysm.

In summary, we herein reported a rare case of hepatic artery pseudoaneurysm associated with a plastic stent insertion and long-term steroid use. The aneurysm was initially difficult to detect. However, it developed after repeated bleeding. We believe that to identify the source of hemobilia, attention should be given to the possible development of a pseudoaneurysm near the plastic stent.

The authors state that they have no Conflict of Interest (COI).

\section{References}

1. Chin MW, Enns R. Hemobilia. Curr Gastroenterol Rep 12: 121129, 2010.

2. Green MH, Duell RM, Johnson CD, Jamieson NV. Haemobilia. Br J Surg 88: 773-786, 2001.

3. Kim KH, Kim TN. Etiology, clinical features, and endoscopic management of hemobilia: a retrospective analysis of 37 cases.
Korean J Gastroenterol 59: 296-302, 2012.

4. Nezu Y, Nakaji S, Fujii H, Ishii E, Hirata N. Pseudoaneurysm caused by a self-expandable metal stent: a report of three cases. Endoscopy 46: 248-251, 2014.

5. Conio M, Caroli-Bosc FX, Buckley M, Chiaramondia M, D’Addazio G, Munizzi F. Massive hematobilia after extraction of plastic biliary endoprosthesis. J Clin Gastroenterol 25: 706, 1997.

6. Wolters F, Ryan B, Beets-Tan R, Dejong C. Delayed massive hemobilia after biliary stenting. Endoscopy 35: 976-977, 2003.

7. Park JY, Ryu H, Bang S, Song SY, Chung JB. Hepatic artery pseudoaneurysm associated with plastic biliary stent. Yonsei Med J 48: 546-548, 2007.

8. Inoue $\mathrm{H}$, Tano $\mathrm{S}$, Takayama $\mathrm{R}$, et al. Right hepatic artery pseudoaneurysm: rare complication of plastic biliary stent insertion. Endoscopy 43 (Suppl 2 UCTN): E396, 2011.

9. Lee SH, Hong SG, Lee KY, et al. Delayed severe hemobilia after endoscopic biliary plastic stent insertion. Clin Endosc 49: 303307, 2016.

10. Green MH, Duell RM, Johnson CD, Jamieson NV. Haemobilia. Br J Surg 88: 773-786, 2001.

11. Mizukami H, Hara S, Kobayashi M, et al. Rupture of abdominal aortic aneurysm associated with long-term steroid therapy-a case report. Legal Med (Tokyo) 16: 33-35, 2014.

The Internal Medicine is an Open Access article distributed under the Creative Commons Attribution-NonCommercial-NoDerivatives 4.0 International License. To view the details of this license, please visit (https://creativecommons.org/licenses/ by-nc-nd/4.0/).

\section{(C) 2018 The Japanese Society of Internal Medicine} Intern Med 57: 49-52, 2018 